\title{
Beti Malia Rahma Hidayati | Efektifitas Pelatihan \\ EFEKTIFITAS PELATIHAN SELF MANAGEMENT SEBAGAI UPAYA MENINGKATKAN SELF REGULATED LEARNING SISWA KELAS VII MTS SUNAN AMPEL PARE
}

\author{
Beti Malia Rahma Hidayati \\ tulhidayati@gmail.com \\ Institut Agama Islam Tribakti Kediri
}

\begin{abstract}
Abstrak
Penelitian ini bertujuan untuk mengetahui efektifitas pelatihan self management sebagai upaya meningkatkan self regulated learning siswa kelas VII di MTs SA Pare. Self regulated learning adalah upaya meningkatkan pencapaian hasil belajar, mengatur diri dalam belajar dan kesanggupan untuk mengelola lingkungan yang kondusif untuk belajar dengan mengikutsertakan kemampuan metakognisi, motivasi instrinsik, dan perilaku belajar aktif. Kemudian Self management merupakan seperangkat prinsip yang meliputi self monitoring, self reward, self contracting, stimulus control yang digunakan untuk meningkatkan keterampilan siswa dalam proses pembelajaran yang diharapkan melalui pelatihan. Jenis penelitian ini adalah true experiment. Populasi adalah siswa kelas VII program reguler. Sampel dipilih dengan purposive sampling, yaitu bagi siswa-siswi yang memiliki kategori self regulated learning rendah. Jumlah sampel ada 18 siswa yang dibagi menjadi kelompok kontrol dan kelompok eksperimen dengan cara random. Adapun tehnik analisa data yang digunakan adalah ANOVA dua arah (Two-way ANOVA). Teknik analisis data yang digunakan adalah teknik analisis statistik dengan memanfaatkan software SPSS versi 20. Berdasarkan hasil analisis, pada faktor kelas diketahui bahwa antara siswa yang diberi dan tidak diberi pelatihan self management memiliki self regulated learning yang berbeda signifikan, rata-rata self regulated learning siswa yang diberi pelatihan lebih tinggi dari pada siswa yang tidak diberi pelatihan.
\end{abstract}

Kata Kunci: Pelatihan, Self Management, dan Self Regulated Learning. 
Beti Malia Rahma Hidayati | Efektifitas Pelatihan

\section{Abstract}

This research aims to validate of self-management training as to improve self-regulate learning achievement for students of VII grade in MTs SA Pare. Self regulated learning is to access of schooling result achievement, to self-organizing in learning and managing ability of environment conducive schooling; Afterwards, Self management are a set of principles that accomodated of selfmonitoring, self-reward, self-contracting, stimulus control for improving students skills in schooling by training. Model of this research is true experiments. For the population choosed from regularly class VII grades student of program; then for sample choosed by properly sampling that is for the students who have low self regulated learning category. It has explored 18 students divided into control group and experimental group by random. For data analysing technique using two ways ANOVA (Two way ANOVA) by using software SPSS version 20. Based on the analysis results, the class who already given and not given self-management training is significantly different, the average self-regulated learning of students who already trained are higher than students who are not trained.

Keywords: Training, Self Management, dan Self Regulated Learning. 


\section{Beti Malia Rahma Hidayati | Efektifitas Pelatihan}

\section{Pendahuluan}

Madrasah merupakan lembaga pendidikan formal yang disediakan bagi peserta didik untuk menuntut ilmu. Selama belajar di madrasah, para peserta didik diwajibkan untuk mengikuti kurikulum yang telah ditetapkan (Agung, 2013). Menurut Susanto (2006) ada banyak faktor yang mempengaruhi keberhasilan seseorang dalam menjalani pendidikannya, salah satu faktor yang turut mempengaruhi keberhasilan siswa dalam mencapai prestasi yang optimal yaitu self regulation (SR).

Pintrich dan Groot (dalam Mustika, 2013) memberikan istilah self regulation dalam belajar dengan istilah self regulation learning, yaitu suatu kegiatan belajar yang diatur oleh diri sendiri, yang didalamnya individu mengaktifkan pikiran, motivasi dan tingkah lakunya untuk mencapai tujuan belajarnya.

Zimmerman (1989) mengatakan bahwa individu yang memiliki self regulation learning merupakan individu yang aktif secara metakognisi, motivasi, dan perilaku di dalam proses belajarnya. Individu yang mampu menentukan tujuan dan menggunakan strategi yang tepat untuk mencapai tujuan belajar. Strategi belajar merupakan tindakan yang menunjukan cara memperoleh informasi tujuan dari setiap strategi difungsikan untuk meningkatkan self regulation baik fungsi pribadi, performa akademis dan lingkungan belajar.

YPI Sunan Ampel memiliki visi untuk mewujudkan insan qur'ani yang berwawasan IMTAQ dan IPTEKS, dengan misi mewujudkan manusia muslim yang bertaqwa kepada Allah SWT, berakhlaqul karimah, cerdas, berpengetahuan luas, cakap, terampil dan bertanggung jawab serta berguna bagi Agama, Nusa, dan Bangsa berdasarkan nilai-nilai Qur'an. Pondok Pesantren Tahfidhil Qur'an Sirojul Ulum menerapkan Integrated Curriculum Based yaitu Kurikulum Pendidikan Nasional, yang dikembangkan sesuai dengan tujuan dan visi, misi pengajaran, serta karakteristik Pondok Pesantren yang bercirikan Agama Islam dan Aswaja. Kegiatan belajar mengajar berlangsung fullday, pukul 07.30-12.00 WIB (Main Curriculum), pukul 13.30-15.30 WIB (Integrated 


\section{Beti Malia Rahma Hidayati | Efektifitas Pelatihan}

Curriculum) dan pukul 18.00-22.00 WIB (Kurikulum Pondok Pesantren).

Sebagai seorang siswa dan juga santri, tuntutan terhadap self regulated learning sangat besar dan jika tidak direspon secara tepat bisa saja menimbulkan dampak yang tidak menguntungkan bagi perkembangan siswa dan santri di masa mendatang, namun fakta di lapangan terlihat bahwa masih banyak siswa dan santri yang tidak mandiri dalam belajar.

Berdasarkan hasil wawancara, diperoleh informasi bahwa siswa yang menempuh pendidikan di MTs Sunan Ampel Pare berasal dari berbagai latar belakang keluarga yang berbeda, namun menurut penyataan guru BK, banyak diantara siswa-siswi tersebut yang motivasi awal menempuh pendidikan di madrasah tersebut karena menuruti keinginan orang tua.

Padatnya materi pelajaran yang harus diselesaikan membuat siswa dan juga santri diharapkan memiliki tingkat self regulated learning yang lebih tinggi dibandingkan dengan siswa yang hanya menempuh pendidikan formal saja. Berkaitan dengan pentingnya self regulated learning bagi siswa, terutama yang juga berperan sebagai santri, maka peneliti tertarik untuk meneliti tentang self regulated learning pada siswa di yayasan Pondok Pesantren Tahfidzul Qur'an Sirojul Ulum. Salah satu madrasah yang berintegrasi dengan pondok pesantren. Hasil pengamatan awal dan wawancara dengan WAKA bidang kurukulum, menggambarkan bahwa siswa yang juga santri mengalami kesulitan dalam mengatur kegiatan belajarnya. Diantara siswasiswi juga sering kali terpengaruh temannya. Misalnya jika ada siswa yang bolos, sering kali siswa yang lain ikut-ikutan dan bergerombol. Walau sebenarnya mereka masih berada di sekitar madrasah atau pondok, yang jelas tidak mengikuti pembelajaran di kelas, sehingga aktifitas madrasah formal (MTs), madrasah diniyah, dan kegiatan pondok tidak dijalani dengan maksimal.

Siswa siswi MTs SA Pare perlu diberikan suatu pelatihan untuk melatih mereka dalam upaya meningkatkan self regulated learning dan secara sadar berkeinginan untuk mengubah 


\section{Beti Malia Rahma Hidayati | Efektifitas Pelatihan}

perilakunya sendiri, khususnya pengelolaan kegiatan belajar yang rendah. Diharapkan dengan pelatihan pengubahan perilaku dapat mengganti perilaku siswa-siswi guna meningkatkan self regulated learning. Pelatihan yang berfungsi untuk mengubah perilaku adalah dengan menggunakan pendekatan behavior. Suatu strategi pengubahan perilaku yang dalam prosesnya dapat mengarahkan perubahan perilaku siswa sendiri merupakan suatu teknik yang disebut dengan self management atau pengelolaan diri (Cormier \& Cormier, 1989).

Self management merupakan serangkaian teknis untuk mengubah perilaku, pikiran, dan perasaan (Yates, 1985). Teknik self management adalah teknik perubahan tingkah laku atau kebiasaan dengan pengaturan dan pemantauan yang dilakukan oleh subjek sendiri dalam bentuk latihan pemantauan diri, pengendalian rangsangan serta pemberian penghargaan pada diri sendiri (Komalasari, 2011). Penelitian ini, akan menguji efektifitas self management sebagai upaya meningkatkan self regulated learning pada siswa di MTs Sunan Ampel Pare.

\section{Self Regulated Learning}

Self regulated learning berasal dari dua kata yaitu self regulated dan learning. Self regulated berarti terkelola, sedangkan leraning adalah belajar. Dapat disimpulkan bahwa self regulated learning secara keseluruhan berarti belajar mengatur diri dalam belajar.

Peneliti menyimpulkan bahwa self regulated learning merupakan upaya meningkatkan pencapaian hasil belajar, mengatur diri dalam belajar dan kesanggupan untuk mengelola lingkungan yang kondusif untuk belajar dengan mengikutsertakan kemampuan metakognisi, motivasi instrinsik, dan perilaku belajar aktif.

Zimmerman dkk (dalam Santrock, 2007) menyimpulkan bahwa ada tiga aspek dalam self regulated learning, adalah metakognisi, motivasi, dan perilaku. Secara singkat, metakognisi dapat diartikan sebagai persepsi individu tentang pengetahuan 


\section{Beti Malia Rahma Hidayati | Efektifitas Pelatihan}

mereka mengenai keadaan dan proses pemikiran mereka sendiri serta kemampuan mereka untuk menjaga dan mengubahnya sesuai keadaan dan proses pemikiran yang meliputi kemampuan individu dalam merencanakan, mengorganisasi atau mengatur, menginstruksi diri, memonitor dan melakukan evaluasi dalam aktifitas belajar.

Menurut Zimmerman (1990) dalam teori sosial kognitif terdapat tiga hal yang mempengaruhi seseorang sehingga melakukan self regulated learning, yakni individu, perilaku dan lingkungan. Faktor individu meliputi pengetahuan, tujuan yang ingin dicapai, kemampuan metakognisi serta efikasi diri. Faktor perilaku meliputi behavior self reaction, personal self reaction serta environment self reaction. Sedangkan faktor lingkungan dapat berupa lingkungan fisik maupun lingkungan sosial, baik lingkungan keluarga, lingkungan sekolah, lingkungan pergaulan dan lain sebagainya.

Pada hakikatnya, karakteristik self regulated learning dapat diamati dari bentuk perbuatan yang mengarah pada tercapainya tujuan belajar. Menurut Santrock (2007), siswa yang mempunyai self regulated learning menunjukkan karakteristik sebagai berikut:

1. Mengatur tujuan belajar untuk mengembangkan pengetahuan dan meningkatkan motivasi.

2. Menyadari hal-hal yang mempengaruhi kondisi emosional dan mempunyai strategi untuk mengatur emosi agar tidak mengganggu kegiatan belajar.

3. Memantau kemajuan yang mendekati target belajar secara periodik, memeriksa strategi belajar yang didasarkan pada kemajuan yang dicapai, mengevaluasi rintangan yang mungkin timbul, dan membuat adaptasi yang diperlukan. 


\section{Beti Malia Rahma Hidayati | Efektifitas Pelatihan}

\section{Self Management}

Self management adalah suatu strategi pengubahan perilaku yang dalam prosesnya individu mengarahkan perubahan perilakunya sendiri dengan suatu teknik atau kombinasi teknik terapetik (Cormier \& Cormier, 1989).

Menurut Gunarsa (2004) self management adalah prosedur dimana individu menggunakan keterampilan dan teknik mengurus diri untuk menghadapi masalahnya, yang dalam terapi tidak langsung diperoleh. Keterampilan tersebut diperoleh pada saat proses konseling karena perubahan dalam perilaku itu harus diusahakan melalui suatu proses belajar (learning) atau belajar kembali (relearning).

Peneliti menyimpulkan bahwa self management, merupakan seperangkat prinsip atau prosedur yang meliputi: 1) pemantauan diri (self monitoring), 2) reinforcement yang positif (self reward), 3) perjanjian dengan diri sendiri (self contracting), 4) penguasaan terhadap rangsangan (stimulus control) yang digunakan untuk meningkatkan keterampilan siswa dalam proses pembelajaran yang diharapkan melalui pelatihan.

Menurut Gunarsa (2004) Self management meliputi pemantauan diri (self monitoring), reinforcement yang positif (self reward), kontrak atau perjanjian dengan diri sendiri (self contracting), dan penguasaan terhadap ransangan (stimulus control).

Pemantauan diri (self monitoring), merupakan suatu proses individu mengamati dan mencatat segala sesuatu tentang dirinya sendiri dalam interaksinya dengan lingkungan. Pemantauan diri bermanfaat untuk asesmen masalah karena data yang bersifat observasional dapat digunakan untuk menguji atau mengubah laporan verbal individu mengenai perilakunya. Dalam pemantauan diri ini biasanya individu mengamati dan mencatat perilakunya, mengendalikan penyebab dari terjadinya masalah (antesedent) dan menghasilkan konsekuensi.

Reinforcement yang positif (self reward), digunakan untuk membantu individu mengatur dan memperkuat perilakunya 
Beti Malia Rahma Hidayati | Efektifitas Pelatihan

melalui konsekuensi yang dihasilkannya sendiri. Banyak tindakan individu yang dikendalikan oleh konsekuensi yang dihasilkannya sendiri sebanyak yang dikendalikan oleh konsekuensi eksternal.

Perjanjian dengan diri sendiri (self contracting), yaitu individu menuliskan peraturan untuk dirinya sendiri selama menjalani proses self management dan akan menanggung resiko dengan program self management yang dilakukannya.

Kendali stimulus (stimulus control) dapat digunakan untuk mengurangi atau meningkatkan perilaku tertentu. Untuk mengurangi perilaku tertentu, isyarat khusus yang merupakan anteseden bagi perilaku tertentu harus dikurangi frekuensinya, ditata kembali, atau diubah waktu dan tempat kejadiannya.

\section{Landasan Teori}

Hamalik (2000) berpendapat bahwa pelatihan adalah suatu proses yang meliputi serangkaian upaya yang dilaksanakan dengan sengaja dalam bentuk pemberian bantuan kepada subjek yang dilakukan oleh tenaga professional kepelatihan dalam suatu waktu yang bertujuan untuk meningkatkan kemampuan subjek.

Pelatihan akan memberikan pengetahuan, kemampuan, keterampilan atau sikap yang relatif baru bagi peserta pelatihan dan akhirnya dapat diaplikasikan hasil pelatihan yang diikuti dalam kehidupan sehari-hari, salah satunya adalah pelatihan dalam bentuk manajemen diri (Mariyati, 2014).

Terry (dalam Mariyati, 2014) menyatakan bahwa menejemen sebagai proses yang khas dan terdiri dari tindakantindakan untuk melakukan suatu perencanaan, pengorganisasian, menggerakkan dan pengawasan yang dilakukan untuk menentukan serta mencapai sasaran yang telah ditetapkan melalui pemanfaatan sumber daya manusia serta sumber-sumber lain. Pelatihan manajemen diri akan memberikan manfaat kepada siswa bahwa siswa dapat melakukan suatu perencanaan perorganisasian dan pengawasan tentang dirinya sendiri dalam melakukan tindakan yang lebih positif, aktif, dan produktif 


\section{Beti Malia Rahma Hidayati | Efektifitas Pelatihan}

Penggunaan teknik self management sangat tepat jika teknik tersebut dikombinasikan dengan informasi cara belajar yang efektif untuk membantu meningkatkan self regulated learning. Self monitoring digunakan untuk memberikan catatan seluruh aktivitas dalam melaksanakan rencana dan jadwal waktu yang belum ditepati. Stimulus kontrol digunakan untuk mengatasi adanya kegagalan dalam menjalankan aktivitas belajar sesuai dengan jadwal yang telah ditentukan karena kebiasaan tersebut, kebiasaan inilah yang dapat diusahakan untuk dikendalikan. Sedangkan self reward digunakan untuk memberikan penguat positif setelah berhasil melaksanakan aktivitas belajar sesuai dengan jadwal yang telah ditentukan. Dengan penguat ini diharapkan aktivitas tersebut dapat dipertahankan atau ditingkatkan.

Self regulated learning adalah upaya meningkatkan pencapaian hasil belajar, mengatur diri dalam belajar dan kesanggupan untuk mengelola lingkungan yang kondusif untuk belajar dengan mengikutsertakan kemampuan metakognisi, motivasi instrinsik, dan perilaku belajar aktif.

Self regulated learning merupakan hal yang sangat penting bagi siswa, terlebih siswa yang berada di pondok pesantren. Siswa sekaligus santri memiliki beban akademik lebih banyak dari pada siswa yang hanya menempuh pendidikan formal saja. Kemandirian dalam belajar sangat dibutuhkan untuk tercapainya hasil belajar yang maksimal. Siswa yang memiliki self regulated learning yang rendah akan berdampak negatif bagi proses pembelajaran siswa. Kegiatan pembelajaran siswa tidak terlaksana sebagaimana yang diharapkan.

Agar dapat belajar secara efektif, siswa harus memiliki kebiasaan dan keterampilan belajar yang baik, diantaranya dengan self management. Kebiasaan dan keterampilan dalam belajar dapat membantu konsentrasi, sehingga tujuan belajar dapat terpenuhi (Loekmono, 1994).

Dalam penelitian ini, pelatihan self management merupakan proses melatih yang telah dipersiapkan sebelumnya 


\section{Beti Malia Rahma Hidayati | Efektifitas Pelatihan}

(dalam bentuk modul pelatihan) untuk mengambil tindakan tertentu yaitu meningkatkan self regulated learning pada siswa MTs Sunan Ampel Kelas VII Pare.

Pelatihan self management, seperti yang telah diuraikan diatas merupakan proses melatih subjek dengan pengaturan diri yang meliputi self monitoring, self reward, self contracting, dan stimulus control. Sementara, yang paling bertanggungjawab untuk membentuk, mengarahkan, memonitor, dan memberikan reinforcement dan punishment tidak lain adalah diri individu itu sendiri. Dengan demikian, jelas sudah bahwa fokus dalam pendekatan self management adalah mengajarkan kepada individu untuk menjadi pengubah yang efektif akan perilakunya sendiri, atau dengan kata lain memberdayakan diri individu itu sendiri dalam mengubah perilaku dirinya. Dengan pelatihan tersebut diharapkan dapat memberikan pengaruh positif, sehingga subjek yang dalam hal ini berperan sebagai siswa dan juga santri di YPI Sunan Ampel dapat memiliki self regulated learning yang tinggi.

\section{Metode Penelitian \\ Desain Penelitian}

Penelitian ini menggunakan pendekatan kuantitatif. Jenis penelitian adalah eksperimen, dimana peneliti akan memberikan suatu perlakuan pada subjek penelitian, guna mengetahui efek dari perlakuan tersebut. Design eksperimen yang digunakan yaitu true experiment.

Jenis design eksperimen yang digunakan adalah posttest only control group design. Subjek dibagi dua secara random kemudian diberi perlakuan pada salah satu kelompok, sedang kelompok yang lain dijadikan sebagai kontrol (Sugiono, 2008).

Design yang dimaksud dapat dilihat pada tabel sebagai berikut: 


\section{Beti Malia Rahma Hidayati | Efektifitas Pelatihan}

Tabel 1: Design Penelitian

\begin{tabular}{|c|c|c|c|c|c|}
\hline Populasi & \multirow{5}{*}{ Y1 } & $\begin{array}{c}\text { Hasil } \\
\text { pretest }\end{array}$ & Random & Pelatihan & Postest \\
\hline \multirow{4}{*}{$\begin{array}{c}\text { Siswa } \\
\text { kelas VII } \\
\text { reguler }\end{array}$} & & Tinggi & - & - & - \\
\hline & & Sedang & - & - & - \\
\hline & & \multirow{2}{*}{ Rendah } & KK & - & \multirow{2}{*}{ Y2 } \\
\hline & & & $\mathrm{KE}$ & $X$ & \\
\hline
\end{tabular}

Keterangan:

$\begin{array}{ll}\mathrm{Y} 1 & =\text { Pre test } \\ \mathrm{KK} & =\text { Kelompok Kontrol } \\ \mathrm{KE} & =\text { Kelompok Eksperimen } \\ \mathrm{X} & \quad=\text { Perlakuan } \\ \mathrm{Y} 2 & \quad=\text { Post test }\end{array}$

Penelitian ini dilakukan berdasarkan rencana sebagai berikut:

1. Melakukan kaji ulang terhadap modul pelatihan.

2. Melakukan training of trainer untuk mempersiapkan trainer.

3. Membentuk subjek menjadi dua kelompok, yaitu kelompok kontrol dan kelompok eksperimen. Subjek yang dilibatkan dalam penelitian ini adalah mereka yang memiliki skor self regulated learning yang rendah. Skor seleksi subjek sekaligus sebagai pretest.

4. Penempatan subjek dalam kelompok dilakukan secara random.

5. Pelaksanaan pelatihan dilakukan dengan bertahap selama 2 minggu.

6. Post test.

Teknik pelatihan self management merupakan seperangkat aturan dan upaya untuk menjalankan praktek bantuan profesional terhadap individu atau kelompok agar mereka dapat mengembangkan potensi dan memecahkan setiap masalahnya dengan mengimplementasikan seperangkat prinsip atau prosedur yang meliputi pemantauan diri (self monitoring), reinforcement yang positif (self reward), perjanjian dengan diri sendiri (self contracting), penguasaan terhadap ransangan 
Beti Malia Rahma Hidayati | Efektifitas Pelatihan

(stimulus control) yang digunakan untuk meningkatkan keterampilan dalam proses pembelajaran yang diharapkan.

Adapun jadwal pelaksanaan pelatihan yaitu:

Tabel 2: Rancangan Pelatihan Self Management

\begin{tabular}{|c|c|c|c|}
\hline NO & WAKTU & KEGIATAN & KETERANGAN \\
\hline 1 & $\begin{array}{l}\text { Hari ke-1 } \\
07.30-08.00 \\
(30 \text { menit })\end{array}$ & $\begin{array}{l}\text { Pembukaan dan } \\
\text { perkenalan }\end{array}$ & $\begin{array}{ll}\text { - } & \text { Perkenalan dengan } \\
\text { fasilitator } \\
\text { - } & \text { Menyamakan } \\
\text { persepsi tentang } \\
\text { tujuan pelatihan }\end{array}$ \\
\hline 2 & $\begin{array}{l}08.00-08.30 \\
(30 \text { menit })\end{array}$ & $\begin{array}{l}\text { Penjelasan } \\
\text { tentang self } \\
\text { management }\end{array}$ & - Metode ceramah \\
\hline 3 & $\begin{array}{l}08.30-09.00 \\
(30 \text { menit })\end{array}$ & $\begin{array}{l}\text { Penjelasan dan } \\
\text { pendalaman } \\
\text { tentang aspek 1: } \\
\text { Pemantauan diri } \\
\text { (self monitoring) }\end{array}$ & - $\quad$ Metode ceramah \\
\hline 4 & $\begin{array}{l}09.00-09.30 \\
(30 \text { menit })\end{array}$ & $\begin{array}{l}\text { Praktik } \\
\text { pemantauan diri } \\
\text { (self monitoring) }\end{array}$ & $\begin{array}{ll}\text { - } & \begin{array}{l}\text { Penugasan selama } 1 \\
\text { minggu }\end{array}\end{array}$ \\
\hline 5 & $\begin{array}{c}\text { Hari ke-2 } \\
07.30-08.45 \\
\text { (75 menit) }\end{array}$ & $\begin{array}{l}\text { Pembahasan } \\
\text { hasil tugas } \\
\text { pemantauan diri } \\
\text { (self monitoring) }\end{array}$ & - $\quad$ Berkelompok \\
\hline 6 & $\begin{array}{l}08.45-09.00 \\
(15 \text { menit })\end{array}$ & $\begin{array}{l}\text { Penjelasan } \\
\text { tentang aspek 2: } \\
\text { Kelola internal } \\
\text { (self } \\
\text { reinforcement) }\end{array}$ & - Metode ceramah \\
\hline 7 & $\begin{array}{l}09.00-09.15 \\
(15 \text { menit })\end{array}$ & $\begin{array}{l}\text { Penjelasan } \\
\text { tentang aspek 3: } \\
\text { Perjanjian } \\
\text { dengan diri } \\
\text { sendiri (self } \\
\text { contracting) }\end{array}$ & $\begin{array}{ll}\text { - } & \text { Metode ceramah } \\
\text { - } & \text { Penugasan: praktik }\end{array}$ \\
\hline 8 & $\begin{array}{l}09.15-09.30 \\
(15 \text { menit })\end{array}$ & $\begin{array}{l}\text { Penjelasan } \\
\text { tentang aspek 4: } \\
\text { Penguasaan } \\
\text { terhadap }\end{array}$ & $\begin{array}{ll}- & \text { Metode ceramah } \\
- & \text { Penugasan: praktik } \\
& \text { (selama } 1 \text { minggu) }\end{array}$ \\
\hline
\end{tabular}




\begin{tabular}{|c|c|l|l|}
\hline & & $\begin{array}{l}\text { rangsangan } \\
\text { (stimulus } \\
\text { control })\end{array}$ & \\
\hline 9 & Hari ke-3 & $\begin{array}{l}\text { Pembahasan } \\
\text { hasil } \\
\text { pelaksanaan } \\
\text { kontrak } \\
\text { perubahan } \\
\text { perilaku }\end{array}$ & $\bullet$ \\
& & Benit $)$ & \\
\hline 10 & $09.00-09.30$ & $\begin{array}{l}\text { Evaluasi dan } \\
\text { penutup }\end{array}$ & $\bullet \begin{array}{l}\text { Metode diskusi/ } \\
\text { tanya-jawab } \\
\text { Pengukuran dengan } \\
\text { skala }\end{array}$ \\
\hline
\end{tabular}

Penelitian ini dilakukan di MTs Sunan Ampel Pare selama 2 minggu. Fasilitator dalam pelatihan ini adalah seorang profesional dari Kediri. Beliau adalah psikolog yang juga bekerja sebagai dosen dan konsultan di Surabaya. Pada saat pelatihan berlangsung, posisi duduk responden diatur dengan model " $U$ " agar fasilitator dapat lebih memperhatikan setiap individu dalam kelompok eksperimen.

\section{Subjek Penelitian}

Subjek yang digunakan dalam penelitian ini yaitu siswa kelas VII di MTs Sunan Ampel Pare, yang termasuk dalam kelas reguler. Semua siswa dari kelas reguler diberikan skala, jumlah data terakhir yang didapat oleh peneliti adalah 114 dari skala yang dikumpulkan oleh subjek.

Berdasarkan hasil pretest yaitu penyebaran skala self regulated learning pada siswa kelas VII dengan jumlah responden 114 siswa, dapat diketahui bahwa kategori self regulated learning siswa kelas VII, yaitu 23 siswa dalam kategori tinggi, 73 siswa dalam kategori sedang, dan 18 siswa dalam kategori rendah. Siswa dengan self regulated learning rendah akan di random untuk menentukan kelompok eksperimen dan kelompok kontrol. 
Beti Malia Rahma Hidayati | Efektifitas Pelatihan

\section{Pengembangan Alat Ukur}

Skala self regulated learning terdiri dari tiga aspek, yaitu metakognisi, motivasi instrinsik, dan perilaku belajar aktif. Bentuk skala menggunakan kategori pilihan dengan metode likert. Alternatif jawaban ada 5, yaitu Sangat Sesuai (SS), Sesuai (S), Netral (N), Tidak Sesuai (TS), Sangat Tidak Sesuai (STS) dengan model pernyataan favorable dan unfavorable (Sedarmayanti, 2002).

\section{Validitas dan Reliabilitas}

Validitas alat ukur digunakan teknik product moment dari Karl Pearson yang mengkorelasikan skor item dengan skor total dari skala yang sama. Sedangkan untuk menguji reliabilitasnya digunakan teknik alpha cronbach. Perhitungan ini dilakukan dengan menggunakan program Statistik Packages for Social Sciences (SPSS) for Windows versi 20.

Standar validitas item yang digunakan dalam penelitian ini adalah rxy $\geq 0,300$ (Azwar, 2003). Dari 30 item yang dipakai, 12 item dinyatakan gugur. Rincian item valid dan item gugur pada skala self regulated learning dapat dilihat pada tabel berikut:

Tabel 3: Aspek, Distribusi, dan Item Gugur Skala Self Regulated

\begin{tabular}{|l|c|c|c|c|}
\hline \multirow{2}{*}{ Aspek } & \multicolumn{3}{|c|}{ Nomor Sebaran Item } & \multirow{2}{*}{$\Sigma$} \\
\cline { 2 - 4 } & \multicolumn{2}{|c|}{ Item Valid } & Item Gugur & $\Sigma$ \\
\cline { 2 - 5 } & $\mathrm{F}$ & $6,7,8$ & $1,2,3,9,10$ & 10 \\
\hline Metakognisi & 4,5 & 16 & $17,18,19,20$ & 10 \\
\hline $\begin{array}{l}\text { Motivasi } \\
\text { instrinsik }\end{array}$ & $11,12,13,14,15$ & $26,28,29,30$ & $23,24,27$ & 10 \\
\hline $\begin{array}{l}\text { Perilaku belajar } \\
\text { aktif }\end{array}$ & $21,22,25$ & 8 & 12 & 30 \\
\hline \multicolumn{1}{|c|}{$\Sigma$} & 10 & & & 10 \\
\hline
\end{tabular}

Hasil uji reliabilitas pada skala self regulated learning setelah menghilangkan item gugur, koefisien reliabilitas adalah 0,820 . Jadi, dapat diketahui bahawa koefisien reliabilitas pada skala self regulated learning dalam kategori reliable. 


\section{Beti Malia Rahma Hidayati | Efektifitas Pelatihan}

\section{Analisa Data}

Dalam penelitian ini tujuan yang ingin dicapai adalah untuk memperoleh data empiris dan menganalisis tentang gambaran self regulated learning siswa kelas VII MTs SA Pare sebelum dan setelah diberi pelatihan self management serta untuk mengetahui perbedaan antara kelompok kontrol dan kelompok ekperimen, sehingga dapat diketahui efektifitas pelatihan self management dalam upaya meningkatkan self regulated learning siswa kelas VII MTs SA Pare.

Data penelitian bersifat kuantitatif dan mengasumsikan bahwa distribusi populasi bersifat normal, maka digunakan statistik parametrik, yaitu statistik yang mengunakan data interval atau selang dan rasio berdasarkan fakta yang bersifat pasti dan berdasarkan sampel. Data parametrik juga dicirikan oleh suatu populasi yang berdisribusi normal dan mempunyai varian yang sama.

Adapun tehnik analisa data yang digunakan adalah ANOVA dua arah (Two-way ANOVA). Teknik analisis data yang digunakan adalah teknik analisis statistik dengan memanfaatkan software SPSS versi 20.

Hasil uji normalitas data untuk masing-masing kelompok pada variabel self regulated learning dengan menggunakan Uji Kolmogorov-Smirnov adalah sebagai berikut:

\begin{tabular}{ccccc}
\multicolumn{4}{c}{ Tabel 4: Hasil Uji Normalitas Kolmogorov-Smirnov $Z$} \\
\hline \multirow{2}{*}{ Kelas } & & $\begin{array}{c}\text { Kolmogorov- } \\
\text { Smirnov } \\
\text { Test }\end{array}$ & Signifikansi & Keterangan \\
\hline Kontrol & Pretest & 1,013 & 0,256 & Normal \\
& Postest & 0,666 & 0,767 & Normal \\
Eksperimen & Pretest & 0,799 & 0,546 & Normal \\
& Postest & 0,432 & 0,992 & Normal \\
\hline
\end{tabular}

Berdasarkan pengujian Kolmogorov-Smirnov $Z$ diatas, didapatkan nilai signifikansi yang lebih besar dari $\alpha=0,05$. Dari pengujian tersebut menunjukkan bahwa data yang akan diuji 


\section{Beti Malia Rahma Hidayati | Efektifitas Pelatihan}

memiliki distribusi normal atau dengan kata lain asumsi normalitas data telah terpenuhi.

Hasil uji homogenitas ragam data pada variabel self regulated learning dengan menggunakan Uji Levene adalah sebagai berikut:

Tabel 5: Hasil Uji Homogenitas Ragam (Levene Test)

\begin{tabular}{cccc}
\hline Variabel & Levene Test & Signifikansi & Keterangan \\
\hline $\begin{array}{c}\text { Self regulated } \\
\text { learning }\end{array}$ & 2,146 & 0,114 & Homogen \\
\hline
\end{tabular}

Berdasarkan pengujian levene test, didapatkan nilai signifikansi yang lebih besar dari $\alpha=0,05$. Dari pengujian tersebut menunjukkan bahwa data yang akan diuji memiliki ragam yang homogen atau dengan kata lain asumsi kehomogenan ragam data terpenuhi.

\section{Hasil dan Pembahasan \\ Hasil Penelitian}

Dalam analisis data akan diuraikan jawaban atas rumusan masalah dan hipotesis untuk memenuhi tujuan dari penelitian. Metode untuk pengumpulan, penyajian, analisis, dan kesimpulan dari data menggunakan statistika deskriptif, yaitu berkaitan dengan kegiatan pencatatan dan peringkasan hasil-hasil pengamatan terhadap kejadian-kejadian atau karakteristikkarakteristik manusia, tempat dan sebagainya, secara kuantitatif.

Untuk memenuhi data tersebut, perhitungannya didasarkan pada distribusi norma yang diperoleh dari mean $(\mu)$ dan standart deviasi $(\sigma)$ hipotetik. Adapun hasil analisisnya yaitu: Tabel 6: Hasil Mean dan Standart Deviasi Kelas kontrol dan Kelas Eksperimen

\begin{tabular}{cccc} 
Kelas & Mean & $\begin{array}{c}\text { Standart } \\
\text { deviasi }\end{array}$ \\
\hline Kontrol & Pretest & 54,44 & 5,769 \\
\hline \multirow{2}{*}{ Eksperimen } & Postest & 54,78 & 5,167 \\
\hline & Pretest & 55,89 & 2,848 \\
\hline & Postest & 70,89 & 4,961
\end{tabular}




\section{Beti Malia Rahma Hidayati | Efektifitas Pelatihan}

Setelah asumsi normalitas dan kehomogenan ragam terpenuhi, langkah selanjutnya yaitu menguji perbedaan antara kelas kontrol dan eksperimen berdasarkan nilai pretest dan postest yang telah diberikan. Untuk itu digunakan analisis Two Way ANOVA. Hasil uji Two Way ANOVA adalah sebagai berikut:

Tabel 7: Hasil Analisis Two Way ANOVA Variabel Self regulated learning

\begin{tabular}{cccccccc}
\hline SK & JK & db & KT & F-hit & $\begin{array}{c}\text { p- } \\
\text { value }\end{array}$ & $\begin{array}{c}\text { F- } \\
\text { tabe } \\
\text { l }\end{array}$ & $\begin{array}{c}\text { Keteranga } \\
\mathrm{n}\end{array}$ \\
\hline Kelas & 693,444 & 1 & 693,444 & 29,924 & 0,000 & $\begin{array}{c}4,14 \\
9\end{array}$ & Signifikan \\
Test & 529,000 & 1 & 529,000 & 22,828 & 0,000 & $\begin{array}{c}4,14 \\
9\end{array}$ & Signifikan \\
$\begin{array}{c}\text { Interaksi } \\
\text { (kelas*test) } \\
\text { Galat }\end{array}$ & 484,000 & 1 & 484,000 & 20,886 & 0,000 & 4,14 & Signifikan \\
Total & 741,556 & 32 & & & & & \\
\hline
\end{tabular}

Berdasarkan tabel di atas, pada faktor kelas diperoleh nilai F-hitung sebesar 29,924 dengan p-value sebesar 0,000. Dari tabel distribusi $\mathrm{F}$ dengan $\mathrm{db} \mathrm{n} 1=1$ dan $\mathrm{n} 2=32$ didapatkan F-tabel sebesar 4,149. Jika F-hitung dibandingkan dengan F-tabel maka Fhitung lebih besar daripada F-tabel $(29,924>4,149)$. Dari pengujian ini didapatkan kesimpulan bahwa terdapat perbedaan yang signifikan self regulated learning antara kelas kontrol dengan kelas ekperimen ( $\mathrm{p}$-value $<0,05$ ). Artinya, antara siswa yang diberi dan tidak diberi pelatihan self management memiliki self regulated learning yang berbeda signifikan, dimana rata-rata self regulated learning siswa yang diberi pelatihan lebih tinggi dari pada siswa yang tidak diberi pelatihan.

Pada faktor test, didapatkan nilai F-hitung sebesar 22,828. Dari tabel distribusi $\mathrm{F}$ dengan $\mathrm{db} \mathrm{n} 1=1$ dan $\mathrm{n} 2=32$ didapatkan $\mathrm{F}$ tabel sebesar 4,149. Jika F-hitung dibandingkan dengan F-tabel maka F-hitung lebih besar dari pada F-tabel $(22,828>4,149)$. Dari pengujian ini didapatkan kesimpulan bahwa terdapat perbedaan yang signifikan self regulated learning antara sebelum dan sesudah diberi pelatihan self management (p-value $<0,05)$. 


\section{Beti Malia Rahma Hidayati | Efektifitas Pelatihan}

Artinya, pemberian pelatihan self management mampu meningkatkan self regulated learning pada siswa.

\section{Pembahasan}

Hasil awal observasi perilaku terhadap siswa-siswi MTs Sunan Ampel Pare kelas VII reguler, peneliti menemukan bahwa siswa-siswi datang ke madrasah lebih dari jam yang ditentukan, sehingga terlambat sampai jam ke dua jam pelajaran. Diantara mereka juga banyak yang keluar kelas saat proses pembelajaran dimulai, ada juga yang tidur didalam kelas.

Berdasarkan hasil wawancara awal dengan guru pengajar, siswa-siswi sering kali tidak mengerjakan tugas, sehingga proses pembelajaran tertunda. Mereka juga sering tidak membawa buku yang membuat proses pembelajaran terhambat. Berbagai alasan diungkap termasuk alasan banyaknya kegiatan yang harus diikuti oleh siswa-siswi yang juga santri pondok di yayasan yang sama.

Siswa dan juga santri tersebut memang dituntut untuk bisa mandiri dalam kesehariannya termasuk mandiri dalam belajar, sedangkan kemandirian setiap anak berbeda-beda. Siswasiswi MTs SA Pare jauh dari orang tua. Kegiatan yang harus diikuti meliputi kegiatan madrasah formal (jenjang MTs), madrasah diniyah, dan kegiatan di pondok. Kegiatan tersebut sebenarnya bisa saja dilakukan dengan baik apabila siswa dapat mengatur proses pembelajarannya dengan baik.

Chamot (dalam Kurniawan, 2013 dan Ellianawati dan Wahyuni, 2010) menyatakan bahwa, self regulated learning atau pembelajaran mandiri adalah sebuah situasi belajar di mana siswa memiliki kontrol terhadap proses pembelajaran tersebut melalui pengetahuan dan penerapan strategi yang sesuai, pemahaman terhadap tugas-tugasnya, penguatan dalam pengambilan keputusan dan motivasi belajar.

Peneliti menggunakan aspek self regulated learning dari Zimmerman yang menyimpulkan bahwa ada tiga aspek dalam self regulated learning, yaitu metakognisi, motivasi, dan perilaku. Aspek tersebut dikembangkan dalam membuat skala yang akan 


\section{Beti Malia Rahma Hidayati | Efektifitas Pelatihan}

digunakan untuk mengukur tingkat self regulated learning subjek sebelum mengikuti pelatihan dan sesudah mengikuti pelatihan.

Agar dapat belajar secara efektif, siswa harus memiliki kebiasaan dan keterampilan belajar yang baik, diantaranya dengan pengelolaan diri (self management). Kebiasaan dan keterampilan dalam belajar dapat membantu konsentrasi, sehingga tujuan belajar dapat terpenuhi (Loekmono, 1994).

Siswa-siswi MTs SA Pare dengan self regulated learning rendah perlu untuk diberikan bantuan agar proses pembelajaran yang sedang dijalani dapat berjalan dengan baik. Sesuai dengan pendapat Hamalik (2000) bahwa pelatihan adalah suatu proses yang meliputi serangkaian upaya yang dilaksanakan dengan sengaja dalam bentuk pemberian bantuan kepada subjek yang dilakukan oleh tenaga professional kepelatihan dalam suatu waktu yang bertujuan untuk meningkatkan kemampuan subjek, maka peneliti menggunakan pelatihan untuk menjawab hipotesis dalam penelitian ini.

Peneliti menggunakan aspek self management menurut Gunarsa, aspek tersebut dijadikan dasar dalam membuat modul pelatihan self management. Berdasarkan pada aspek self regulated learning dan self management, terhadap keterkaitan hubungan antara keduanya. Diharapkan dengan keterkaitan tersebut dapat memberikan dampak yang positif. Tidak dipungkiri bahwa dalam prosesnya akan banyak faktor yang mempengaruhi self regulated learning dan self management. Dalam prosesnya, untuk meningkatkan self regulated learning, siswa diberikan pemahaman dan penugasan berupa jadwal kegiatan harian sebagai bentuk pembelajaran self monitoring, setelah dievaluasi siswa menuliskan perjanjian keseriusan pelaksanaan program sebagai bentuk self contracting, memberikan simbol dan pujian jika berhasil melaksanakan program sebagai bentuk self reward, dan pengkondisian sebagai bentuk stimulus control.

Zimmerman (1989) mengatakan bahwa individu yang memiliki self regulation learning merupakan individu yang aktif secara metakognisi, motivasi, dan perilaku di dalam proses 


\section{Beti Malia Rahma Hidayati | Efektifitas Pelatihan}

belajarnya. Individu yang mampu menentukan tujuan dan menggunakan strategi yang tepat untuk mencapai tujuan belajar.

Sebagai seorang siswa dan juga santri, tuntutan terhadap self regulated learning sangat besar dan jika tidak direspon secara tepat bisa saja menimbulkan dampak yang tidak menguntungkan bagi perkembangan siswa dan santri di masa mendatang, namun fakta di lapangan terlihat bahwa masih banyak siswa dan santri yang tidak mandiri dalam belajar.

Siswa-siswi MTs SA Pare dituntut untuk bisa mandiri dalam segala aktifitas hariannya. Keseharian mereka yang jauh dari orang tua dan tinggal dipondok membuat kemandirian, utamanya dalam belajar sangat dibutuhkan. Tujuan awal keberadaan mereka adalah belajar, sehingga kemandirian dalam belajar sangat dibutuhkan. Siswa diharapkan memiliki self regulated learning yang tinggi. Apabila siswa memiliki self regulated learning yang rendah akan mengakibatkan kesulitan dalam menerima materi pelajaran sehingga hasil belajar mereka menjadi tidak optimal (Adicondro, 2011).

Menurut pernyataan kepala MTs SA Pare, sebenarnya siswa-siswi dikelas VIII dan IX juga perlu untuk diberikan perlakuan, bahkan di kelas VII juga banyak siswa yang dirasa belum mandiri dalam belajar. Melihat aspek self regulated learning, banyak siswa yang belum aktif dalam metakognisi, motivasi, dan juga perilakunya dalam belajar, namun saat penelitian dilakukan siswa-siswi tersebut jarang masuk madrasah/ lebih sering bolos, sehingga hanya ada datanya saja dan belum bisa berpartisipasi dalam penelitian.

Suatu strategi pengubahan perilaku yang dalam prosesnya dapat mengarahkan perubahan perilaku siswa sendiri merupakan suatu teknik yang disebut dengan self management atau pengelolaan diri (Cormier \& Cormier, 1989).

Pada penelitian ini, analisis data menggunakan media SPSS versi 20 yang dilakukan untuk mengetahui perbedaan self regulated learning siswa yang telah diberikan pelatihan self management dan yang tidak diberikan pelatihan. Berdasarkan 


\section{Beti Malia Rahma Hidayati | Efektifitas Pelatihan}

hasil analisis, diketahui bahwa antara siswa yang diberi dan tidak diberi pelatihan self management memiliki self regulated learning yang berbeda signifikan, dimana rata-rata self regulated learning siswa yang diberi pelatihan lebih tinggi dari pada siswa yang tidak diberi pelatihan. Artinya, pemberian pelatihan self management mampu meningkatkan self regulated learning pada siswa.

Self regulated learning adalah upaya meningkatkan pencapaian hasil belajar, mengatur diri dalam belajar dan kesanggupan untuk mengelola lingkungan yang kondusif untuk belajar dengan mengikutsertakan kemampuan metakognisi, motivasi instrinsik, dan perilaku belajar aktif. Pelatihan self managemen, seperti yang telah diuraikan pada kajian teori merupakan proses melatih subjek dengan pengaturan diri yang meliputi self monitoring, self reward, self contracting, dan stimulus control. Penggunaan teknik self management sangat tepat jika teknik tersebut dikombinasikan dengan informasi cara belajar yang efektif untuk membantu meningkatkan self regulated learning.

\section{Simpulan dan Saran \\ Simpulan}

Berdasarkan hasil analisis dan pembahasan, dapat disimpulkan bahwa antara siswa yang diberi dan tidak diberi pelatihan self management memiliki self regulated learning yang berbeda signifikan. Hasil tersebut dapat dibuktikan dari tabel distribusi $\mathrm{F}$ dengan $\mathrm{db} \mathrm{n} 1=1$ dan $\mathrm{n} 2=32$ didapatkan F-tabel sebesar 4,149. Jika F-hitung dibandingkan dengan F-tabel maka Fhitung lebih besar daripada F-tabel $(29,924>4,149)$. Dari pengujian ini diketahui perbedaan yang signifikan self regulated learning antara kelas kontrol dengan kelas ekperimen ( $\mathrm{p}$-value < $0,05)$. Artinya, antara siswa yang diberi dan tidak diberi pelatihan self management memiliki self regulated learning yang berbeda signifikan, dimana rata-rata self regulated learning siswa yang diberi pelatihan lebih tinggi dari pada siswa yang tidak diberi pelatihan. 
Beti Malia Rahma Hidayati | Efektifitas Pelatihan

Berdasarkan pada faktor test, didapatkan nilai F-hitung sebesar 22,828. Dari tabel distribusi $\mathrm{F}$ dengan $\mathrm{db} \mathrm{n} 1=1$ dan $\mathrm{n} 2=$ 32 didapatkan F-tabel sebesar 4,149. Jika F-hitung dibandingkan dengan F-tabel maka F-hitung lebih besar daripada F-tabel $(22,828>4,149)$. Dari pengujian ini didapatkan kesimpulan bahwa terdapat perbedaan yang signifikan self regulated learning antara sebelum dan sesudah diberi pelatihan self management $(\mathrm{p}$ value < 0,05). Berdasarkan analisis tersebut, dapat diambil kesimpulan bahwa pemberian pelatihan self management mampu meningkatkan self regulated learning.

\section{Saran}

Beberapa saran yang diajukan, diantaranya yaitu:

1. Untuk Siswa MTs SA Pare, diharapkan siswa yang telah memiliki self regulated learning tinggi dapat mempertahankannya dan yang masih dalam kategori rendah dapat meningkatkannya, salah satu caranya dengan praktek menggunakan self management (self monitoring, self reward, self contracting, dan stimulus control).

2. Untuk Pihak MTs SA Pare, dapat melatih siswa agar memiliki self regulated learning tinggi dengan melakukan pelatihan self management yang bisa diprogramkan oleh guru BK sebagai layanan yang ditawarkan di madrasah. Modul pelatihan self management dapat dilihat pada lampiran.

3. Untuk peneliti selanjutnya diharapkan dapat melakukan penelitian lebih luas mengenai penggunaan teknik self management untuk meningkatkan self regulated learning siswa agar dapat meminimalisir jumlah siswa yang mengalami self regulated learning rendah, serta lebih memperhatikan faktorfaktor yang dapat mempengaruhi self regulated learning. 


\section{Beti Malia Rahma Hidayati | Efektifitas Pelatihan}

\section{Daftar Pustaka}

Agung, Anak Putu Chintya Putri Suardana dan Nicholas Simarmata. (2013) Hubungan antara Motivasi Belajar dan Kecemasan pada Siswa Kelas VI Sekolah Dasar di Denpasar Menjelang Ujian Nasional. Program Studi Psikologi, Fakultas Psikologi, Universitas Udayana. Jurnal Psikologi Udayana, Vol. 1, (No. 1. ISSN: 2354-5607), Hal: 203-212.

Arikunto, Suharsimi. (2006). Prosedur Penelitian Suatu Pendekatan Praktek, Edisi VI. Jakarta: Rineka Cipta.

Aziz, Rahmat. (2010). Psikologi Eksperimen. Handout Perkuliahan (tidak dipublikasikan).

Azizi. (2013). Self Regulated Learning Strategis Among Bachelor Science Degree Students of Male and Female: A Comparative Study. Acme International Journal of Multidiscriplinary Research. Volume - I, (Issue - XII), Hal: $232-236$.

Azwar, Saifuddin. (2003). Penyusunan Skala Psikologi. Yogyakarta: Pustaka Belajar.

Budiyani, Kondang dan Sri Mulyani Martaniah. (2011). Pelatihan Manajemen Diri untuk Meningkatkan Kepatuhan Diet pada Penderita Diabetes Melitus Tipe II. PSYCHO IDEA, (ISSN 1693-1076), Hal: 78-97.

Cormier, L.J. \& Cormier, L.S. 1989. Interviewing Strategies for

Helpers. 7 ed Montery, California: Brooks/Code Publishing Company.

Darmayanti. (2008). Efektifitas Intervensi Keterampilan Self Regulated Learning dan Keteladanan dalam Meningkatkan Kemampuan Belajar Mandiri dan Preatasi Belajar Mahasiswa Pendidikan Jarak Jauh. Jurnal Pendidikan

Terbuka dan Jarak Jauh. Volume 9, (Nomor 2), Hal: 68-82.

Djiwandoro. (2002). Psikologi Pendidikan. Jakarta: PT. Grasindo.

Ellen. (2008). Self Efficacy for Self-Regulated Learning: A Validation Study. Journal Educational and Psychological Measurement. SAGE. (DOI: 10.1177/001316440730847; 443) Hal: 68.

Ellianawati dan Wahyuni. (2010). Pemanfaatan Model SelfRegulated Learning Sebagai Upaya Peningkatan Kemampuan Belajar Mandiri pada Mata Kuliah OPTIK. 
Beti Malia Rahma Hidayati | Efektifitas Pelatihan Jurnal Pendidikan Fisika Indonesia. Vol. 6 (ISSN: 1693-124). Hal: 35-39.

Gunarsa, D. Singgih. (2004). Konseling dan Psikoterapi. Jakarta: Gunung Mulia.

Hamalik, Oemar. 2000. Perencanaan Pengajaran Berdasarkan Pendekatan Sistem. Jakarta: PT. Bumi Aksara.

Ishtifa, Hanny. (2011). Pengaruh Self Efficacy dan kecemasan Akademis terhadap Self Regulated Learning Mahasiswa Fakultas Psikologi Universitas Islam Negeri Jakarta. Skripsi. Fakultas Psikologi Universitas Islam Negeri Syarif Hidayatullah Jakarta.

Isnaini, Faiqotul. (2014). Strategi Self Management untuk Meningkatkan Kedisiplinan Belajar. Tesis. Naskah publikasi. Program Magister Sains Psikologi Universitas Muhammadiyah Surakarta

Kartono, K. (2007). Bimbingan dan Dasar-dasar Pelaksanannya. Jakarta: CV. Rajawali.

Komalasari, G. dkk. (2011). Teori dan Teknik Konseling. Jakarta: PT. Indeks.

Kramarski. (2013). New Perspectives on Integrating Self Regulated Learning at School. Journal Hindawi Publishing Corporation. Education Research International. Volume 2013, (ID 498212), Hal: 4.

Kurniawan, Rizki. (2013) Hubungan antara Self Regulated Learning dengan Prokrastinasi Akademik pada Mahasiswa Jurusan Psikologi Universitas Negeri Semarang. Skripsi. Fakultas Ilmu Pendidikan Universitas Negeri Semarang.

Latipah. (2010). Strategi Self Regulated Learning dan Prestasi Belajar: Kajian Meta Analisis. Jurnal Psikologi. Volume 37, (No. 1), Hal: 110-129.

Latipun. (2008). Psikologi Eksperimen. Malang: UMM Press.

Loekmono, L. (1994). Belajar Bagaimana Belajar. Jakarta: BPK. Gunung Mulia.

Magno. (2011). The Predictive Validity of the Academic Self Regulated Learning Scale. The International Journal of Education and Psychological Assessment. Vol. 9 (1).

Mahadi. (2013). The Role of Meta-Cognitive Self Regulated Learning Strategies in Enhancing Language Performance: A the Oretical and Empirical Review. Journal of Asian Scientific Research. Asian Economicand Social Society AESS. 3 (No. 6), Hal: 570-577. 


\section{Beti Malia Rahma Hidayati | Efektifitas Pelatihan}

Mappiare, Andi. (2006). Kamus Istilah Konseling \& Terapi. Jakarta: PT RajaGrafindo Persada.

Mariyati, Ika. (2014). Pelatihan Manajemen Diri dengan Pendekatan Choice Theory untuk Menurunkan Kecenderungan Merokok pada Remaja. Fakultas Psikologi Universitas Muhammadiyah Sidoarjo. Jurnal Ilmiah Psikologi Terapan. Vol. 02, (No. 01. ISSN: 2301-8267).

Muhibbin. (2005). Psikologi Pendidikan Suatu Pendekatan Baru. Bandung: PT. Remaja Rosdakarya.

Mulyani. (2013). Hubungan antara Manajemen Waktu dengan Self Regulated Learning pada Mahasiswa. Educational Psychology Journal. EPJ 2 (1) ISSN 2252-634X.

Mustika (2013). Hubungan antara Manajemen Waktu dengan Self Regulated Learning pada Mahasiswa. Educational Psychology Journal. Vol. 02 (No. 01. ISSN 2252-634X). Hal: 43-48.

Nursalim, Mochamad. (2013). Strategi \& Intervensi Konseling. Jakarta: Indeks.

Rahil, Eka. (2013). Motivasi Berprestasi dan Self Regulated Learning. Jurnal Online Psikologi, Vol.01, (No.02, Thn. 2013. ISSN: 2301-8259).

Rusyan, Kusdinar, dan Zainal. (1992). Pendekatan dalam Proses Belajar Mengajar. Bandung: PT. Remaja Rosdakarya.

Sadeghy. (2014). The Relationship Between Learners GoalOriented and Self-Regulated Learning And Their Endorsement of L2 Learning Strategies. International Journal of Language Learning and Applied Linguistics World (IJLLALW). Volume 5 (No. 2); 574-593. ISSN (online): 2289-2737 \& ISSN (print): 2289-3245.

Santrock, J.W. (2007). Psikologi Pendidikan. Edisi Kedua. Jakarta: PrenadaMedia Group.

Sugiono. (2008). Metode Penelitian Kuantitatif Kualitatif dan $R \&$ D. Bandung: Alfabeta.

Susanto, Handy. (2006). Mengembangkan Kemampuan SelfRegulation Untuk Meningkatkan Keberhasilah Akademik Siswa. Journal Pendidikan Penabur. Vol.5. (No.7), Hal. 6471

Syah, M. (2012). Psikologi Belajar. Jakarta: PT. Raja Grafindo Persada. 
Beti Malia Rahma Hidayati | Efektifitas Pelatihan

Wolters, C.A. Pintrich, P.R, dan Karabenick, S.A. (2003). Assesing Academic Self Regulated learning. Conference on Indicators of Positive Development: Cild Trends. Hal: 8-24.

Yates, Brian T. (1985). Self-Management: The Science and Art of Helping Yourself. California: Wadsworth Publishing Company.

Zimmerman, B.J. (1990). Self Regulated Learning and Academic Achievement: An Overview. Educational Psychologist. Vol. 25 (No. 1), Hal: 3-17.

Zimmerman, Barry J. (1989). A Social Cognitive View of SelfRegulated Academic Learning. Journal of Educational Psychology. Vol. 81. (No. 3), Hal. 329-339. Washington: American Psychological Association. 